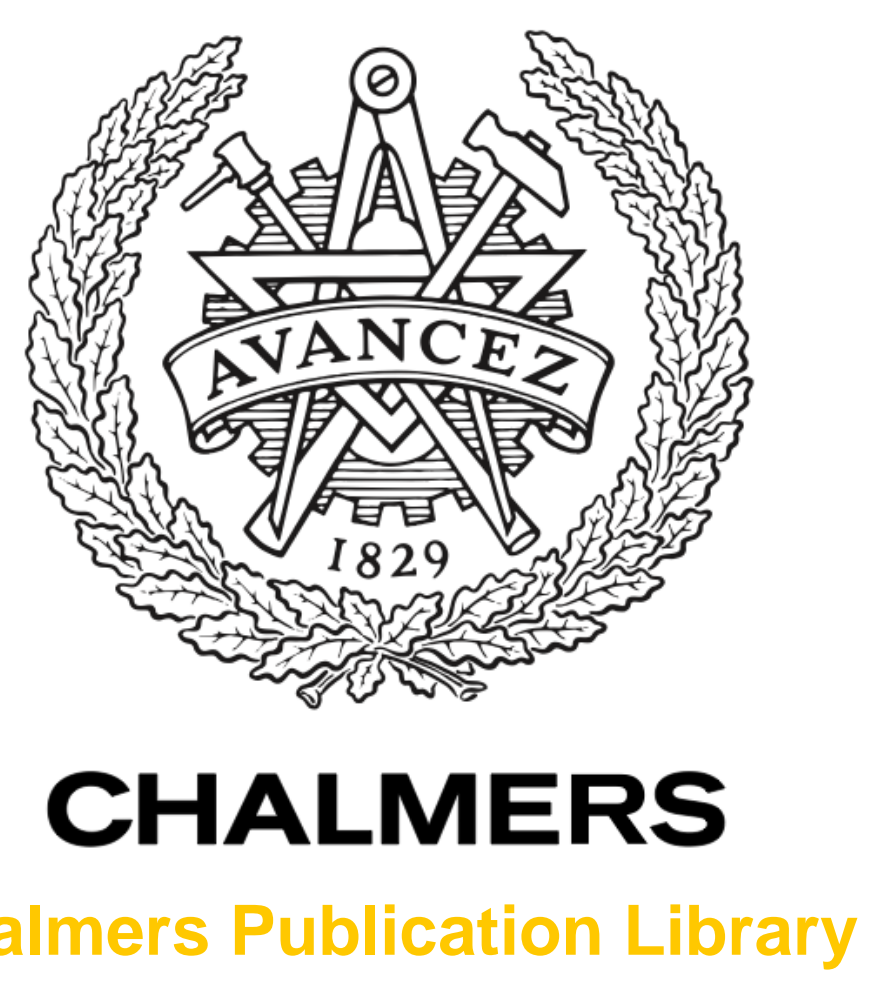

Chalmers Publication Library

\title{
Arrangements and Applications of Self-grounded Antennas
}

This document has been downloaded from Chalmers Publication Library (CPL). It is the author's version of a work that was accepted for publication in:

8th European Conference on Antennas and Propagation, EuCAP 2014, The Hague, The Netherlands 6-11 April 2014

Citation for the published paper:

Yang, J. ; Al-Rawi, A. ; Raza, H. (2014) "Arrangements and Applications of Self-grounded Antennas". 8th European Conference on Antennas and Propagation, EuCAP 2014, The Hague, The Netherlands 6-11 April 2014 pp. 79 - 83.

http://dx.doi.org/10.1109/EuCAP.2014.6901697

Downloaded from: http://publications.lib.chalmers.se/publication/203785

Notice: Changes introduced as a result of publishing processes such as copy-editing and formatting may not be reflected in this document. For a definitive version of this work, please refer to the published source. Please note that access to the published version might require a subscription.

Chalmers Publication Library (CPL) offers the possibility of retrieving research publications produced at Chalmers University of Technology. It covers all types of publications: articles, dissertations, licentiate theses, masters theses, conference papers, reports etc. Since 2006 it is the official tool for Chalmers official publication statistics. To ensure that Chalmers research results are disseminated as widely as possible, an Open Access Policy has been adopted.

The CPL service is administrated and maintained by Chalmers Library. 


\title{
Arrangements and Applications of Self-grounded Antennas
}

\author{
Jian Yang*, Ali Al-Rawi*, Hasan Raza*, Per-Simon Kildal*, Akmed A. Kishk ${ }^{\dagger}$, \\ *Dept. of Signals and Systems, Chalmers University of Technology, SE-41296 Gothenburg, Sweden \\ jian.yang@chalmers.se \\ ${ }^{\dagger}$ Concordia University, Canada
}

\begin{abstract}
The self-grounded antenna is a new type of compact ultra-wideband antennas with simple geometries. One of the characteristics of this type antenna is its high flexibility: the configuration of the antenna can be arranged in many different ways for different applications. In this paper, we overview the typical arrangements of the self-grounded antennas, and their performance for different applications.
\end{abstract}

Index Terms-Self-grounded antenna, ultra-wideband, MIMO antenna

\section{INTRODUCTION}

There is an increasing demand of ultra-wideband antennas in wireless communication devices (allow communication in several frequency bands) and other systems (sensing systems, tracking and positioning system, medical monitoring, etc.). The use of wideband signals is associated with many positive aspects and advantages as, for example, described in [1].

Different UWB antennas are required for different UWB applications. Many UWB antennas have been developed [2]-[5]. We presented a new type of UWB antennas - the self-grounded antennas in the paper [6]-[9]. One of the characteristics of this type antenna is its high flexibility: the configuration of the antenna can be arranged in many different ways. Several arrangements of the basic geometry of self-grounded antenna and their applications are overviewed below.

\section{MOdel OF WORKING PRINCIPLE}

We can use one halfwave tilted V-form electric dipole and two halfwave magnetic dipoles, as shown in Fig. 1, to model the self-grounded Bow-Tie antenna for the radiation performance. The electric dipole represents the radiating electric current on the Bow-Tie surface, and the two magnetic dipoles represent the loop electric current caused by the selfgrounding. The electric dipole can be written as

$$
\mathbf{J}=\left\{\begin{array}{lr}
I_{0} j\left(l^{\prime}\right) \hat{\boldsymbol{l}}_{1}, & -\frac{l_{e}}{2}<l^{\prime}<0 \\
I_{0} j\left(l^{\prime}\right) \hat{\boldsymbol{l}}_{2}, & 0<l^{\prime}<\frac{l_{e}}{2}
\end{array}\right.
$$

where

$$
j\left(l^{\prime}\right)=\frac{\sin \left[k\left(l_{e} / 2-l^{\prime}\right)\right]}{\sin \left(k l_{e} / 2\right)}
$$

and $k=2 \pi / \lambda$ is the wave number. The tilted angle $\alpha$ for the dipole in the modeling is the same as the tilted angle of the arms in the real antenna.
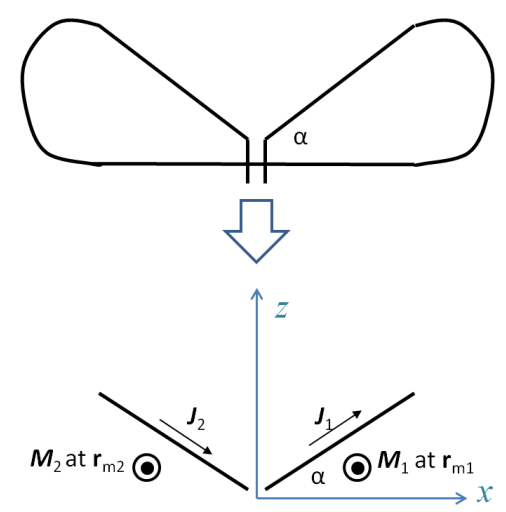

Fig. 1. Modeling of a self-grounded Bow-Tie antenna by a Huygens' source: a halfwave electric dipole and two halfwave magnetic dipoles.

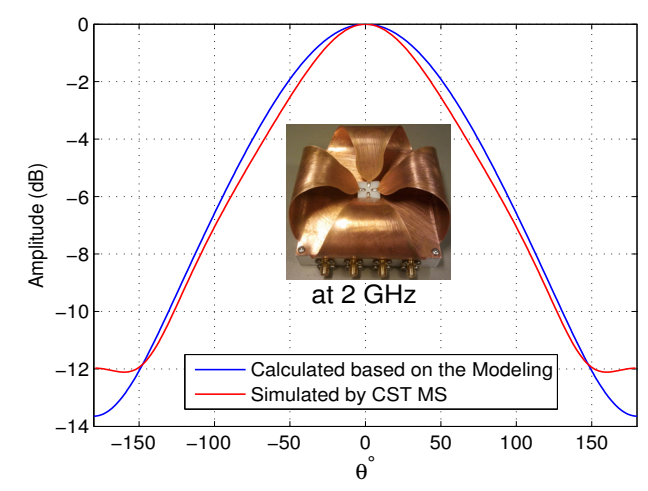

Fig. 2. Radiation pattern in $\varphi=0$ plane of a $1.5-3 \mathrm{GHz}$ dual-polarized selfgrounded Bow-Tie antenna: calculated based on the modeling and simulated by CST MS.

The magnetic dipoles can be written as

$$
\mathbf{M}=\left\{\begin{array}{lr}
M_{0} m\left(y^{\prime}\right) \hat{\boldsymbol{y}}, & -\frac{l_{m}}{2}<y^{\prime}<0 \\
M_{0} m\left(y^{\prime}\right) \hat{\boldsymbol{y}}, & 0<y^{\prime}<\frac{l_{m}}{2}
\end{array}\right.
$$

where $M_{0}=\eta I_{0}(\eta=377 \mathrm{ohms}$, free space impedance),

$$
m\left(y^{\prime}\right)=\frac{\sin \left[k\left(l_{m} / 2-y^{\prime}\right)\right]}{\sin \left(k l_{m} / 2\right)}
$$

and the locations of $r_{m 1}$ and $r_{m 2}$ are defined as

$$
\begin{aligned}
& r_{m 1}=\left(l_{e} \cos \alpha / 2,0, l_{e} \sin \alpha / 4\right) \\
& r_{m 2}=\left(-l_{e} \cos \alpha / 2,0, l_{e} \sin \alpha / 4\right)
\end{aligned}
$$




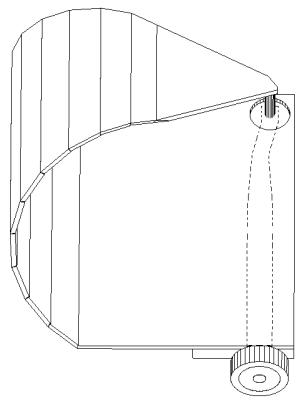

(a)

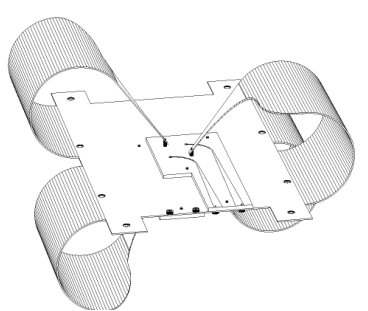

(c)

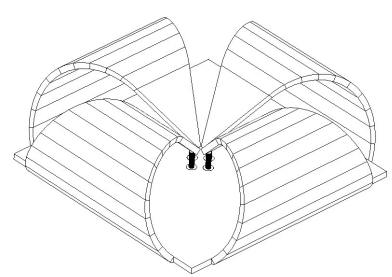

(e)

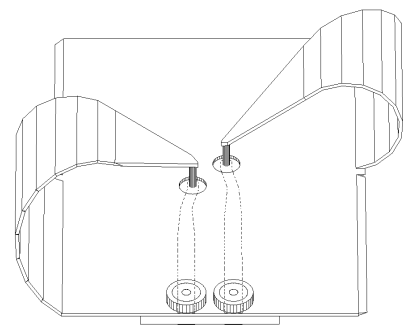

(b)

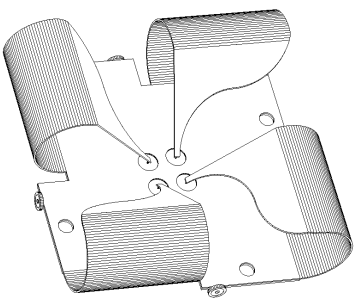

(d)

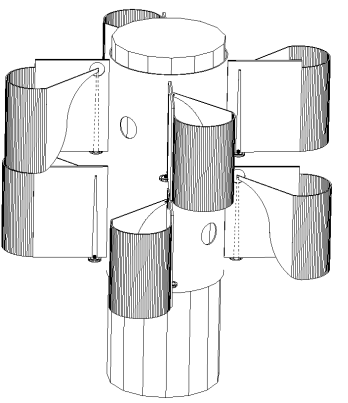

(f)
Fig. 3. The self-grounded antenna and different arrangements: (a) basic geometry; (b) two-branch; (c) four-branch double-sided; (d) four-branch onesided; (e) dual-polarized; (f) eight-branch poster-mounted.

Fig. 2 shows the calculated radiation pattern based on the above model for a $1.5-3 \mathrm{GHz}$ self-grounded Bow-tie antenna at $2 \mathrm{GHz}$ [10], and the simulated one by using CST MS. It can be seen that the agreement is very good.

\section{ARRANGEMENTS}

The basic geometry of the self-grounded antenna is shown in Fig. 3(a). Then, we can arrange the basic geometry in different ways: two-branch self-grounded antenna (Fig. 3(b)), four-branch double-sided self-grounded antenna (Fig. 3(c)), four-branch one-sided self-grounded antenna (Fig. 8(d)), dual-polarized directional self-grounded antenna (Figs. 8(d) and 3(e)), eight-branch poster-mounted self-grounded antenna (Fig. 3(f)), etc.

\section{PERFORMANCE}

In this section, we will illustrate different performance of different arrangements of the self-grounded antenna.

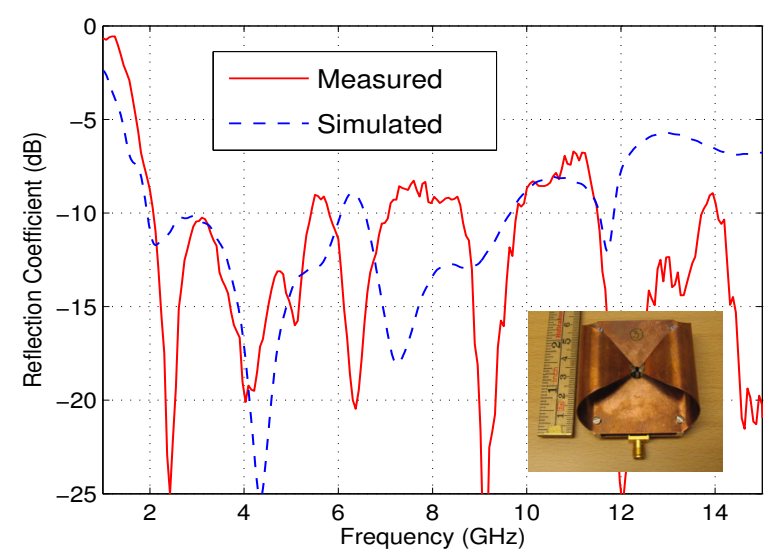

Fig. 4. Reflection coefficient of a $2-15 \mathrm{GHz}$ linearly-polarized self-grounded Bow-Tie antenna.

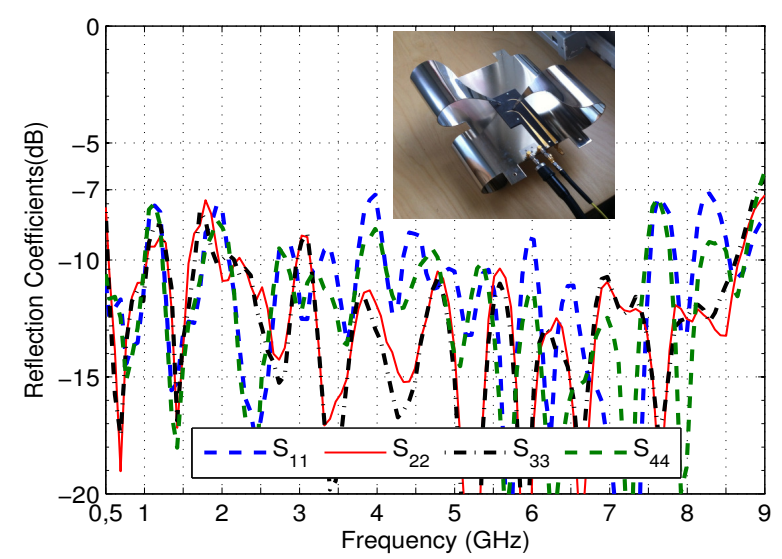

Fig. 5. Reflection coefficient of a $0.5-9 \mathrm{GHz}$ MIMO self-grounded monopole array antenna.

\section{A. Low Reflection Coefficient over Wideband}

A low reflection coefficient of self-grounded antennas has be achieved over a ultra-wideband. Fig. 4, Fig. 5 and Fig. 6 shows the reflection coefficients of a linearly-polarized selfgrounded Bow-tie antenna below $-8 \mathrm{~dB}$ over $2-15 \mathrm{GHz}$ (7.5:1 bandwidth), a MIMO self-grounded monopole array antenna below $-7 \mathrm{~dB}$ over $0.5-9 \mathrm{GHz}$ (18:1 bandwidth), and a dual polarized self-grounded Bow-tie antenna below $-10 \mathrm{~dB}$ over 1.5-3 GHz(2:1 bandwidth), respectively.

\section{B. Fast Time-domain Impulse Response}

The self-grounded antenna has a very fast time response due to its characteristic geometry: no multiple resonant geometry. Fig. 7 shows the measured time-domain impulse response when two self-grounded Bow-tie antennas face to each other. It can be seen that there is almost no ringing after the pulse.

\section{Good Axial Ratio over Wide Coverage}

One of interesting characteristics of the self-grounded Bowtie antenna is that the axial ratio (AR) of the circularly polarized far-field function of the antenna is good over a wide 


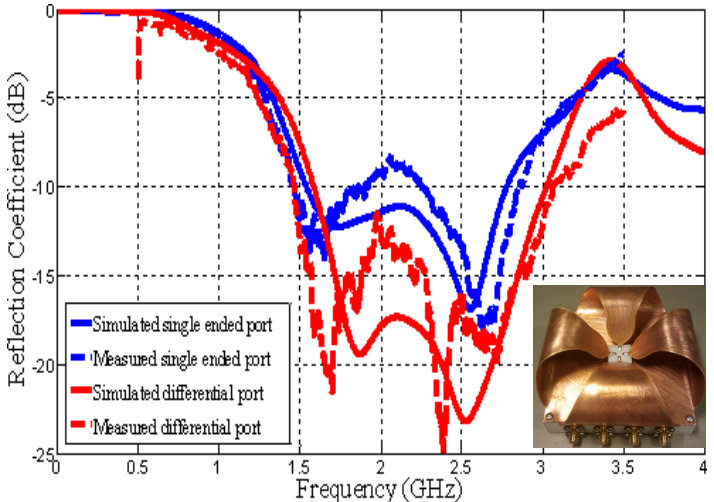

Fig. 6. Reflection coefficient of a $1.5-3 \mathrm{GHz}$ dual-polarized self-grounded Bow-Tie antenna.

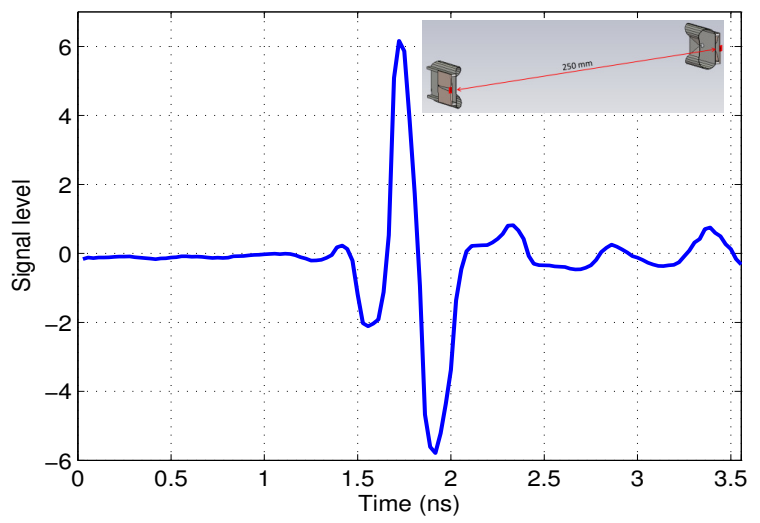

Fig. 7. Measured time-domain impulse response of two self-grounded antennas separated by $250 \mathrm{~mm}$ in the face-to-face configuration.

coverage with a wideband. Fig. 8 shows the calculated AR based on the simulated far-field function of a $0.5-1.6 \mathrm{GHz}$ dual polarized self-grounded Bow-tie antenna. From it, we can see that over the frequency band, the AR is below $-4 \mathrm{~dB}$ over $\theta \subset\left(0,60^{\circ}\right)$. Note that when $\theta$ is smaller than $30^{\circ}$, the $\mathrm{AR}$ is below $-2 \mathrm{~dB}$ over the whole band. This characteristic makes the antenna a perfect candidate for receiving antenna for satellite communication and GPS on a moving vehicle, such on boats, on trains and on cars.

\section{Constant Phase Center}

Due to the self-grounded geometry, the antenna has a stable phase center location, which is similar to the Eleven antenna [11], [12]. Fig. 9 shows the phase center of a $1.5-3 \mathrm{GHz}$ dualpolarized Bow-tie antenna. It can be seen that over 1.6-2.2 $\mathrm{GHz}$, the phase center location is within $\pm 2 \mathrm{~mm}$.

\section{E. Good Polarization Balance}

By different arrangements, the self-grounded antennas can be used as good MIMO antennas, with a good polarization balance over all directions. The polarization balance is defined as the ratio of power between two orthogonal components, which is a function of direction $(\theta, \varphi)$ [13]. Fig. 10 shows

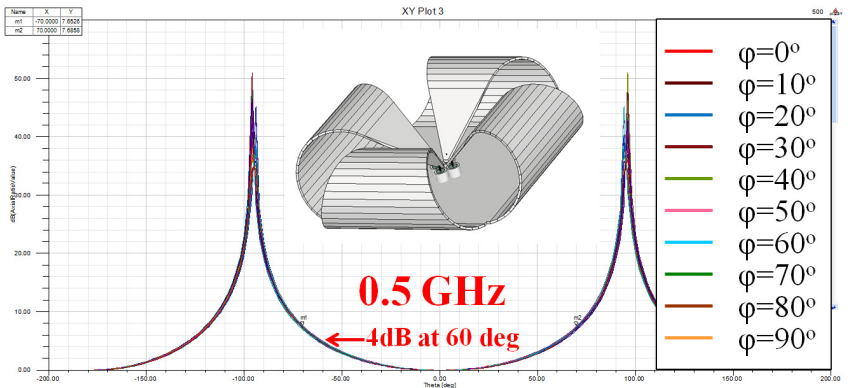

(a)

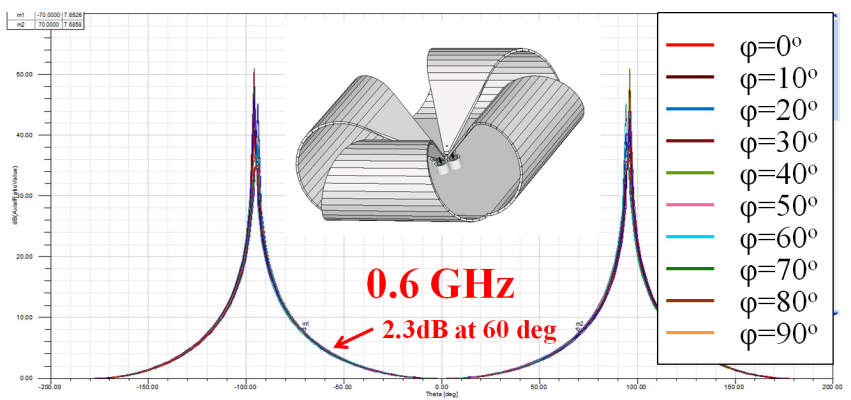

(b)

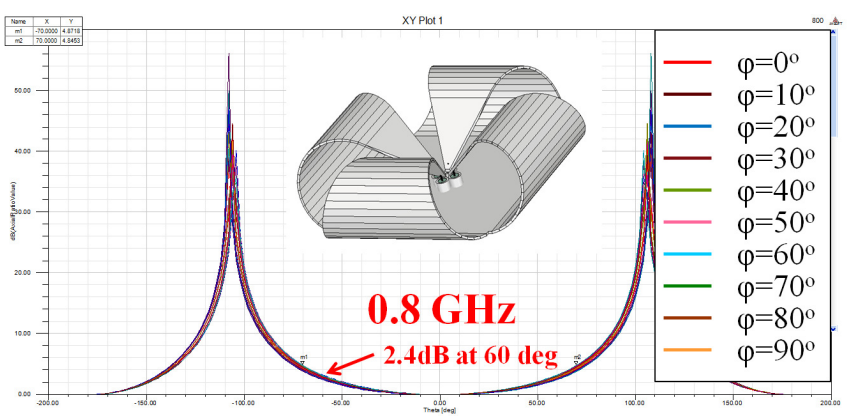

(c)

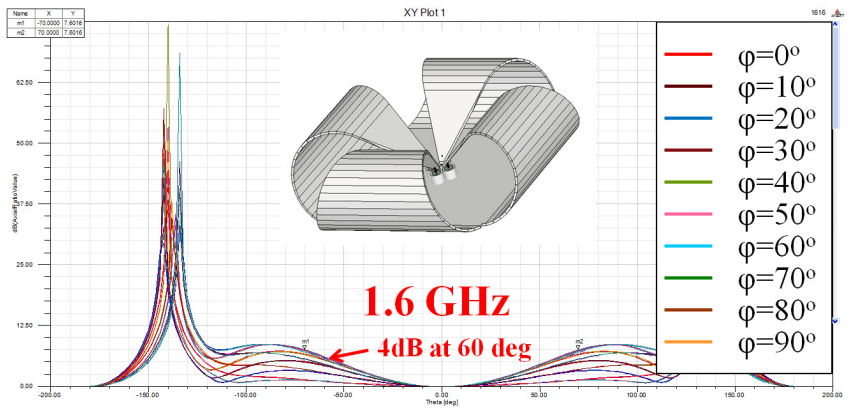

(d)

Fig. 8. Simulated axial ratio over $\theta \subset\left(0,60^{\circ}\right)$ in a frequency range of $0.5-1.6 \mathrm{GHz}$.

the calculated polarization balance of a $0.4-15 \mathrm{GHz}$ MIMO antenna, which shows a good performance.

\section{F. High Diversity Gain}

Fig. 11 shows the measured and simulated apparent diversity gain with maximal ratio combining (MRC) scheme for the proposed antenna, used as a 2-, 3-, or 4-port MIMO antenna. A high diversity gain has been achieved by this double-sided 


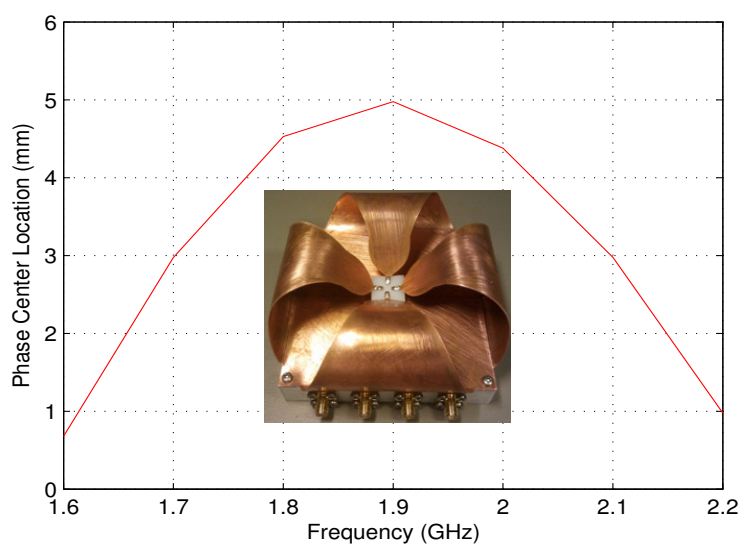

Fig. 9. Calculated phase center location based on simulated radiation function of $1.5-3 \mathrm{GHz}$ dual-polarized Bow-tie antenna.

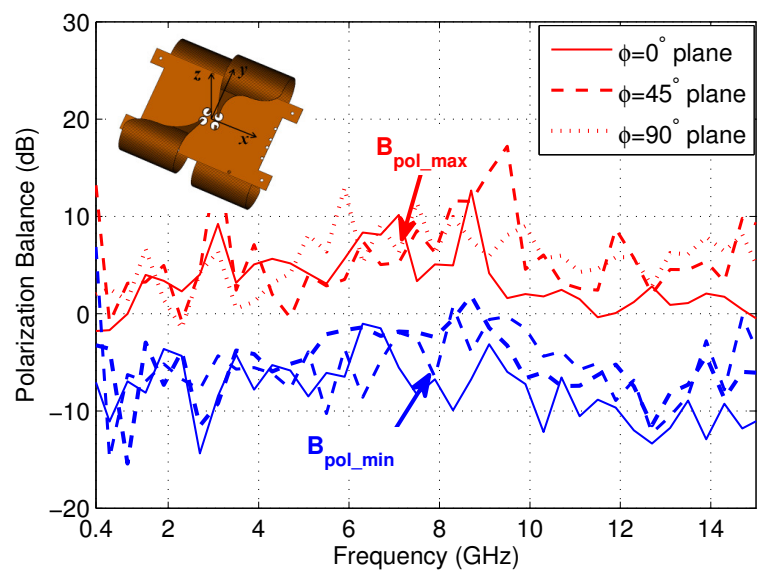

(a)

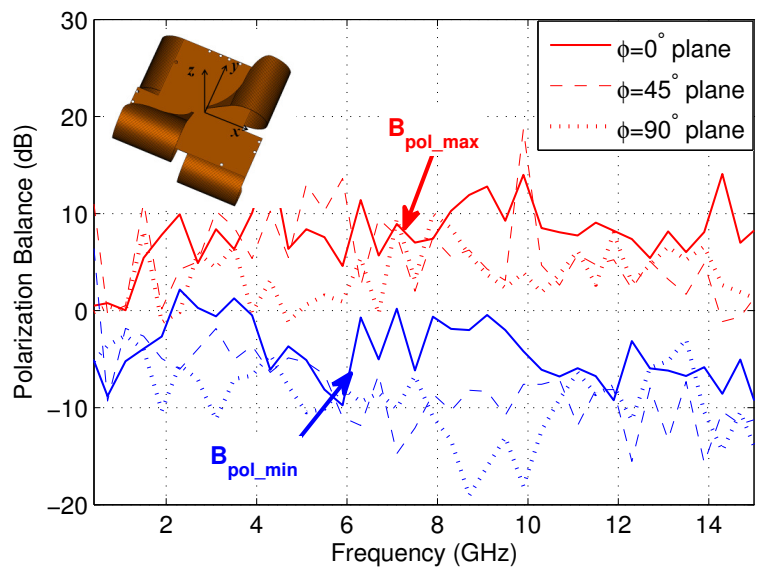

(b)

Fig. 10. Calculated polarization balance of (a) the MIMO antenna in [8] and (b) a variation of this MIMO antenna.

tapered self-grounded monopole array arrangement.

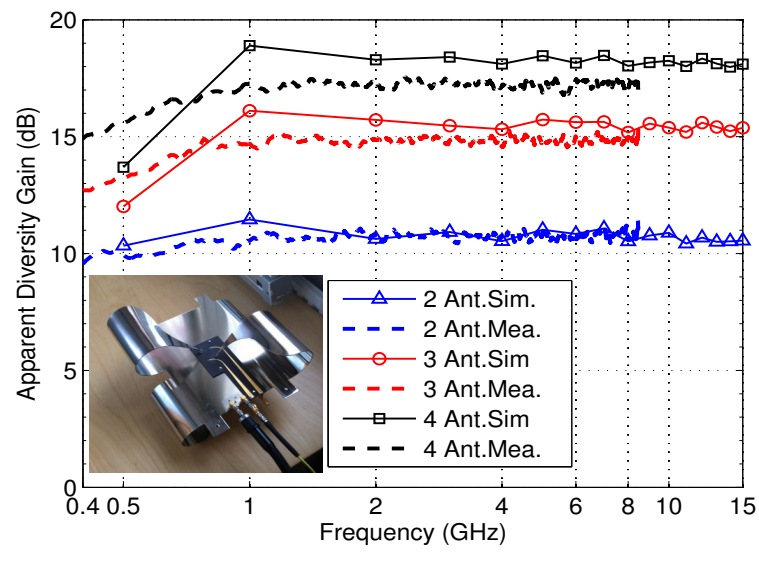

Fig. 11. Apparent diversity gain with maximum ratio combining technique (MRC) using a four-branch double-sided self-grounded antenna.

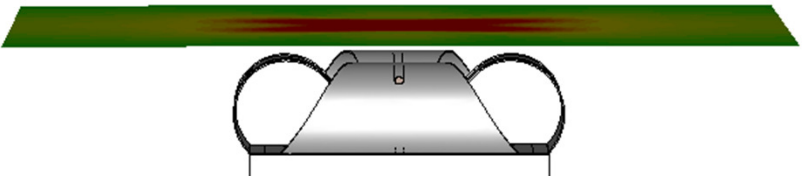

(a)

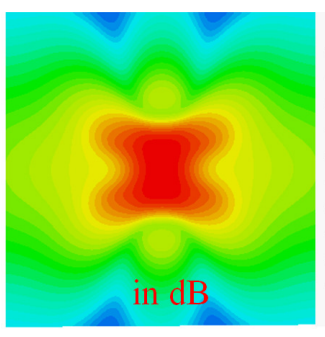

(b)
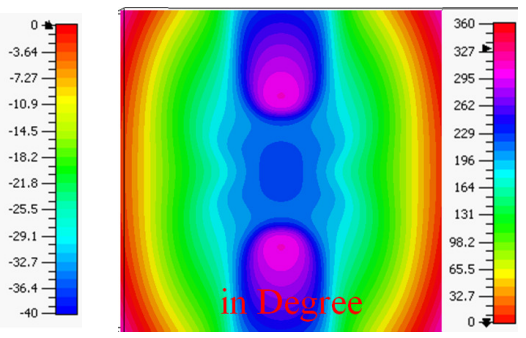

(c)
Fig. 12. Simulated aperture distribution of $1.5-3 \mathrm{GHz}$ Bow-tie antenna (a) amplitude (b) and phase (c).

\section{G. Near Field Aperture}

Fig. 12 shows the near field aperture of the self-grounded Bow-tie antenna, which is a good candidate in near field detection applications.

\section{Applications}

Due to the flexibility and good performance, the selfgrounded antennas have been applied or under investigation to the following areas: i) UWB indoor and through-wall radar with precise ranging and tracking due to the wideband performance, fast time-domain impulse response and the compact size [14]; ii) wideband MIMO systems due to the large coverage, good polarization balance and high diversity gain [8], [15]; iii) stroke diagnosis system due to the good near field aperture distribution [16]; iv) UWB SAR imaging of near field object for industrial process [17], [18]; v) breathing and heartbeat detection [19]. vi) receiving antenna on moving vehicles, such as on boats, trains and cars, because of its good 
Axial Ratio over large elevation angles and low profile. More applications will be found to this type of antennas.

\section{CONCLUSIONS}

We have presented an overview of different arrangements and performances of the self-grounded antennas. We believe that this new type of UWB antenna can find more applications in different areas.

The self-grounded antenna is protected by patents [20], [21].

\section{REFERENCES}

[1] M. Win, D. Dardari, A. Molisch, W. Wiesbeck, and J. Zhang, "History and applications of UWB," Proceedings of the IEEE, vol. 97, no. 2, pp. 198-204, 2009.

[2] A. K. Amert and K. W. Whites, "Miniaturization of the biconical antenna for ultrawideband applications," IEEE Transactions on Antennas and Propagation, vol. 57, no. 12, pp. 3728-3735, 2009.

[3] Y. Mushiake, "Self-complementary antennas," IEEE Antennas Propag. Mag., vol. 34, no. 6, pp. 23-29, Dec. 1992.

[4] P. J. Gibson, "The vivaldi aerial," Proc. 9th European. Microwave Conference, pp. 101-105, 1979.

[5] J. Yin, J. Yang, M. Pantaleev, and L. Helldner, "The circular Eleven antenna: a new decade-bandwidth feed for reflector antennas with a high aperture efficiency," IEEE Transactions on Antennas and Propagation, vol. 61, no. 8, 2013.

[6] J. Yang and A. Kishk, "A novel low-profile compact directional ultrawideband antenna: the self-grounded Bow-Tie antenna," IEEE Trans. Antennas Propagat., vol. 60, no. 3, pp. 1214-1220, March 2012.

[7] —_, "The self-grounded Bow-Tie antenna." Spokane, Washington: 2011 IEEE AP-S International Symp. on Antennas Propag., 3-8 July 2011.

[8] A. Al-Rawi, J. Yang, C. Orlenius, and M. Franzén, "The double-sided 4-port bow-tie antenna: A new compact wideband mimo antenna," in 2013 7th European Conference on Antennas and Propagation (EuCAP), 2013, pp. 3731-3735.

[9] A. Kishk, "UWB antennas for detections and communications," in Antennas and Propagation (EuCAP), 2013 7th European Conference on. IEEE, 2013, pp. 764-766.

[10] H. Raza, A. Hussain, J. Yang, and P.-S. Kildal, "Wideband compact 4-port dual polarized self-grounded Bowtie antenna," submited to IEEE Transactions on Antennas and Propagation, 2014.

[11] R. Olsson, P.-S. Kildal, and S. Weinreb, "The Eleven antenna: a compact low-profile decade bandwidth dual polarized feed for reflector antennas," IEEE Trans. on Antennas Propagat., vol. 54, no. 2, pp. 368-375, Feb. 2006.

[12] J. Yang, M. Pantaleev, P.-S. Kildal, B. Klein, Y. Karandikar, L. Helldner, N. Wadefalk, and C. Beaudoin, "Cryogenic 2-13 GHz Eleven feed for reflector antennas in future wideband radio telescopes," IEEE Transactions on Antennas and Propagation, vol. 59, no. 6, pp. 1918-1934, 2011.

[13] A. Al-Rawi, A. Hussain, J. Yang, M. Franzen, C. Orlenius, and A. A. Kishk, "A new compact wideband mimo antenna the double-sided tapered self-grounded monopole array," submited to IEEE Transactions on Antennas and Propagation, 2014.

[14] Y. Yu, J. Yang, T. McKelvey, and B. Stoew, "A compact UWB indoor and through-wall radar with precise ranging and tracking," International Journal on Antenna and Propagations, vol. 2012, no. Article ID 678590 , 11 pages, 2012. doi:10.1155/2012/678590.

[15] A. Hussain, P. Kildal, A. Al-Rawi, and J. Yang, "Efficiency, correlation, and diversity gain of UWB multiport self-grounded bow-tie antenna in rich isotropic multipath environment," in 2013 International Workshop on Antenna Technology (iWAT), 2013, pp. 336-339.

[16] S. Abtahi, J. Yang, and S. Kidborg, "A new compact multiband antenna for stroke diagnosis system over 0.5-3 ghz," Microwave and Optical Technology Letters, vol. 54, no. 10, pp. 2342-2346, 2012.

[17] S. S. Fayazi, J. Yang, and H.-S. Lui, "UWB SAR imaging of nearfield object for industrial process applications," in 2013 Proceedings of the Seventh European Conference on Antennas and Propagation (EuCAP2013), 2013, pp. 1-5.
[18] S. S. Fayazi, H.-S. Lui, and J. Yang, "Microwave imaging of nearfield object using ultra-wideband synthetic aperture radar algorithm," in 2012 IEEE Antennas and Propagation Society International Symposium (APSURSI). IEEE, 2012, pp. 1-2.

[19] Q. Jian, Y. Yu, J. Yang, P. Bjorkholm, and T. McKelvey, "Detection of breathing and heartbeat by using a simple UWB radar system," in submitted to 2014 European Conference on Antennas and Propagation (EuCAP2014), 2014.

[20] J. Yang and A. A. Kishk, "Self-grounded Bow-Tie antenna," PCT Patent PCT/SE2010/1001072-6, 2010.

[21] J. Yang, A. Al-Rawi, M. Franzén, C. Orlenius, and A. A. Kishk, "Self grounded Antenna Arrangement," PCT Patent Application SE-12511663, owened by Gapwaves AB Sweden, 2 October 2012. 